\title{
Glucose sensing module - is it time to integrate it into real-time perioperative monitoring? An observational pilot study with subcutaneous sensors
}

\author{
Iveta Poljakova ${ }^{a}$, Eva Elsikovaa , Rudolf Chlup ${ }^{a, b}$, Stanislav Kalabusc, Petr Hasalac, Jana Zapletalova ${ }^{d}$
}

\begin{abstract}
Aims. To explore the feasibility of subcutaneous continuous glucose monitoring (CGM) in perioperative settings and to evaluate the perioperative development of glycaemia in persons with diabetes mellitus or impaired glucose tolerance by means of CGM.

Methods. Monitoring by means of Guardian ${ }^{\circledR}$ REAL-Time CGMS (Medtronic, Nortridge, USA) in 20 perioperative periods. Sensor was inserted on the day before surgery and continued for 3 days with some exceptions.

Results. Full implementation of the method was successful in the intensive care unit setting only. No electromagnetic interference and no side effects were found. The Wilcoxon signed-rank test revealed no significant difference between sensor and laboratory analyser values. Pearson's correlation coefficients of the values obtained by sensor and the Wellion Linus glucometer were 0.875 for the whole perioperative period, 0.866 for the intraoperative period and 0.903 for the first perioperative day. A decline in sensor accuracy on the $6^{\text {th }}$ day was registered in one case. 16 monitored cases (80\%) did not meet the criteria for safe plasma glucose range. Hypoglycaemia was found in $4(20 \%)$ cases. There was an association between grade of the perioperative dysglycaemia and need for reoperation within the next 3 months. The most frequent perioperative glycaemic patterns are demonstrated.

Conclusion. Subcutaneous CGM is safe offering detailed insight into glucose homeostasis in the dynamic perioperative period. Laboratory confirmation of sensor plasma glucose concentration by approved laboratory analyser is still necessary. The potentional benefits of maintaining patients within a safe glucose range should be comfirmed by future studies.
\end{abstract}

Key words: perioperative glycaemic control, continuous glucose monitoring, stress-induced dysglycaemia, subcutaneous glucose sensors, diabetes mellitus, surgery

Received: November 27, 2012; Accepted with revision: June 17, 2013; Available online: June 25, 2013

http://dx.doi.org/10.5507/bp.2013.049

${ }^{a}$ Department of Physiology, Faculty of Medicine and Dentistry, Palacky University Olomouc, Czech Republic

${ }^{b}$ Department of Internal Medicine II - Gastroenterology and Hepatology, University Hospital Olomouc and Faculty of Medicine and Dentistry, Palacky University Olomouc

'Department of Surgery, Prerov Regional Hospital, Central Moravia Region Inc, Prerov

${ }^{d}$ Department of Medical Biophysics, Faculty of Medicine and Dentistry, Palacky University Olomouc

Corresponding author: Iveta Poljakova, e-mail: iveta.poljakova@seznam.cz

\section{INTRODUCTION}

Plasma glucose (PG) homeostasis in intensive care settings is a subject of ongoing intense investigation.

In patients with diabetes mellitus (DM) or impaired glucose tolerance, stress-induced dysglycaemia is enhanced due to impaired glycaemia control mechanisms. Together with preexisting vasculopathy and immune response dysfunction, it is responsible for the more frequent postoperative complications in these patients.

The prevalence of both type 1 and type $2 \mathrm{DM}$ is epidemically growing and persons with DM undergo surgical procedures more frequently than the normal population, with prolonged length of hospital stay and higher mortality rates. Improvement of their postoperative outcome is therefore a challenge for anaesthesiologists.

Hyperglycaemia (providing there is no external glucose input) is a metabolic marker of surgical stress and therefore the glycaemia trend should be of interest for all care providing medical staff.
The impact of degree of glycaemic control on clinical outcome has been studied intensively over the past decade and has been the subject of well-known controversies. Tight glycaemic control, adopted as a standard of care after the publication of the Leuven study ${ }^{1}$ in 2001, was abandoned, after new randomized controlled trials revealed the high risk of severe hypoglycaemia ${ }^{2,3}$. On the other hand, there is indisputable evidence linking uncontrolled perioperative hyperglycaemia with a negative outcome. It was also demonstrated that hyperglycaemiadecreasing interventions reduce morbidity and mortality in all patients, regardless of a prior history of diabetes ${ }^{4-9}$. Hyperglycaemia leads to fluid shifts, electrolyte dysbalances, ketoacidosis, hyperosmolarity, dehydration and impaired neutrophil function predisposing to infection and impaired wound healing. An additional benefit could result from more intensive insulin therapy - insulin is not only a glycaemia-reducing agent with anticatabolic effects but also a growing factor with substantial wound healing properties, observed even in topical application ${ }^{10,11}$. 
Current guidelines recommend a sensible ("reasonable, achievable, and safe") glycaemia management with more liberal PG target values in the the near-normal range between 4.4 - 10 and $11.1 \mathrm{mmol} / \mathrm{L}$ (79 - 180 or $200 \mathrm{mg} /$ $\mathrm{dL})\left(\right.$ ref. $^{12-15}$ ). The accent is on maintaining glycaemia stability with respect to the physiological circadian PG rhythm existing even in critically ill patients ${ }^{16}$. The consensus statement on glycaemic control in critically ill patients is regularly upgraded ${ }^{17}$. It is recommendable to adhere to these guidelines to avoid "preventable complications"18.

So far, there has been limited evidence on the occurrence of perioperative hypoglycaemia episodes, which could be difficult to avoid by the means of standard intermittent PG sampling.

To meet appropriate PG target in the dynamic perioperative period, frequent and exact PG monitoring is essential and therefore a proper monitoring technology needed.

Central laboratory devices (CLD), most accurate for that purpose, do not provide real-time data. The gold standard for the intensive care setting, an automated blood gas analyser, is not always available. Point-of-care meters can be an unreliable estimate for plasma glucose ${ }^{19}$, especially with hypotension and hypoperfusion ${ }^{20}$ and could lead to harmful clinical errors especially in the hypoglycaemic range ${ }^{21}$. Many of them lack FDA-required accuracy standards and cannot be regarded as an exact measuring device during the perioperative haemodynamic and haemoglobin shifts ${ }^{22,23}$. All these common types of monitoring are intermittent, their efficacy depends on the frequency of blood sampling and some of the dangerous PG deviations could remain undetected.

Intravenous blood glucose monitors are under development, but they possess risks associated with intravenous or even central venous access, potential interference with i.v. solutions, and a need for anticoagulation in some of them ${ }^{24,25}$.

The highlight of current technological endeavour in diabetology is the creation of a "an artificial pancreas". The intensive care setting with patient's energy balance under control is ideal for closed-loop system clinical testing and the results are promising also in the perioperative period ${ }^{26-31}$. Nevertheless, these technologies are also invasive and expensive.

Continuous glucose monitoring systems (CGMS) with subcutaneous sensors have been used since 1999. Originally, they were designed for out-patient self-monitoring. At present, they are undergoing rapid development. There are several approved devices in common use - Guardian® REAL-Time CGMS (Medtronic), Dexcom TM Seven ${ }^{\circledR}$ Plus (DexCom) and FreeStyle Navigator ${ }^{\circledR}$ (Abbott) use enzyme-based technology; the GlucoMen (Menarini) is based on microdialysis. Each marketed device has a particular accuracy profile ${ }^{32}$.

The advantage of subcutaneous CGMS is minimal invasivity, acceptable price and continual mode of glucose monitoring.

On the other hand, there is a concern over their reliability in the acute care setting ${ }^{33}$. Goldberg used them in a medical ICU in 2004 and found $98.7 \%$ of the paired val- ues clinically acceptable; he evaluated CGM as a reducer of glycaemia fluctuations and a promising research tool ${ }^{34}$. Others found it useful for reducing hyperglycaemic episodes $^{35}$. The analysis of two prospective randomized trials demonstrated clinically sufficient accuracy and safety ${ }^{36,37}$ even in patients on vasopressors ${ }^{38}$. Some reject the use of subcutaneous sensors in the ICU setting ${ }^{39,40}$.

The pioneering work in the use subcutaneous sensors in a perioperative setting was a study by Hannah Piper - in pediatric cardiac surgery. The CGMS performed well in the setting of hypothermia, inotrope use, and oedema ${ }^{41}$. Other perioperative experience is limited ${ }^{42}$.

In personalised medicine, the safe continuous mode of monitoring would be ideal for patients at high risk of perioperative dysglycaemia.

\section{SUBJECTS AND METHODS}

We analysed clinical and laboratory data obtained from 20 perioperative CGMS-monitored cases undergoing low extremity surgery because of vascular complications. The entry criteria were: preexisting DM or impaired glucose tolerance, planned lower extremity surgery for vascular complications and informed consent of the participant. The study was conducted in 3 centres: the University Hospital Olomouc (6 participants) and two nearby regional hospitals (Prerov, 9 participants; Kromeriz, 5 participants) in the period from June $1^{\text {st }}$, 2010 to June $30^{\text {th }}, 2011$. Ethical approval was provided by the Ethics Committee and a written informed consent was obtained from all study participants. These were 17 adults, median age 69 years, 12 (65\%) were male, 9 (53\%) were persons with diabetes mellitus type 2 (DM 2) treated with insulin, 5 (29\%) were persons with DM 2 treated with oral antidiabetic agents, one was a person with DM 2 treated with a combination of insulin and oral diabetic agents, one was a person with DM 2 on a diet, and one was a person with impaired glucose tolerance on corticosteroid medication. All the patients were scheduled for lower extremity surgery because of vascular complications of diabetes mellitus and/or atherosclerosis. Three of the participants were monitored repeatedly also during their reoperation several weeks after the first surgery. Altogether, 20 cases of continuous perioperative monitoring were evaluated, CGM data were collected in 71 perioperative days. The list of cases is shown in Table 1.

The Guardian ${ }^{\circledR}$ REAL-Time CGMS (Medtronic Nortridge, CA, USA) and a Medtronic SOF-SENSOR ${ }^{\mathrm{TM}}$ were used. The system consists of a miniature sensor placed in the subcutaneous fat (we used the abdominal or upper arm region with respect to the planned operation), a transmitter joined to the sensor, and an external monitor wirelessly communicating with the sensor, with a signal reach of approximately $2.5 \mathrm{~m}$. The glucose sensing is based on the glucose oxidase method, generating an electrical current. The values are registered every $10 \mathrm{~s}$ and averaged every $5 \mathrm{~min}$. The resulting value is transmitted to the monitor and processed by an algorithm converting the value of glucose concentration in interstitial fluid (IF) 
Table 1. List of cases.

\begin{tabular}{|c|c|c|c|c|c|c|c|c|}
\hline$\sum_{0}^{\infty}$ & 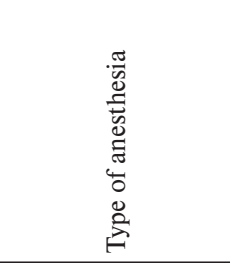 & 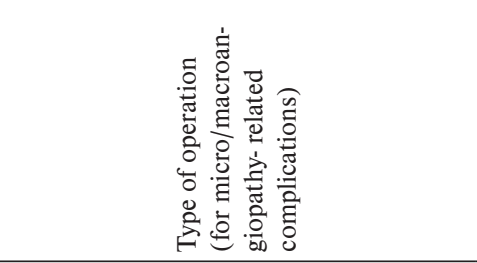 & 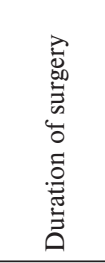 & 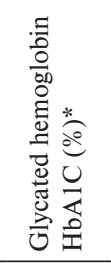 & 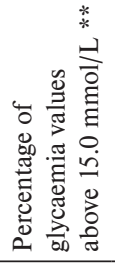 & 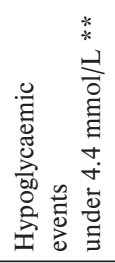 & 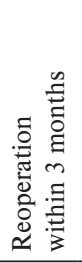 & $\sqsupseteq \stackrel{*}{*}$ \\
\hline DM 2, diet & Spinal anesthesia & Transfemoral amputation & $45 \mathrm{~min}$ & 4.6 & 0 & & & \\
\hline DM 2, insulin treatment & General anesthesia & Partial foot amputation (Chopart) & $20 \mathrm{~min}$ & 8.7 & 11.7 & & + & \\
\hline DM 2, insulin treatment & General anesthesia & Foot abscess, incision and drainage & $20 \mathrm{~min}$ & 4.7 & 2.9 & & & \\
\hline \multirow[t]{2}{*}{ DM 2, insulin treatment } & Local anesthesia & Necrectomy of digits & $20 \mathrm{~min}$ & 4.8 & 1.9 & & + & \\
\hline & Spinal anesthesia & Amputation below knee & $60 \mathrm{~min}$ & no value & 29.2 & & + & $65 \mathrm{~h}$ \\
\hline DM 2, insulin treatment & General anesthesia & Amputation of digits & $40 \mathrm{~min}$ & 7.4 & 2.8 & & + & \\
\hline IGT, corticosteroid medication & General anesthesia & Partial foot amputation & $30 \mathrm{~min}$ & 3.6 & 0 & & & \\
\hline \multirow[t]{2}{*}{ DM 2, insulin treatment } & General anesthesia & Amputation of digits & $20 \mathrm{~min}$ & 15.5 & 49.6 & & + & $69 \mathrm{~h}$ \\
\hline & General anesthesia & Partial foot amputation & $25 \mathrm{~min}$ & 7.5 & 0 & & & \\
\hline DM 2, oral diabetic agents & General anesthesia & Amputation of digits & $20 \mathrm{~min}$ & 5.2 & 6.3 & & + & \\
\hline DM 2, oral diabetic agents & General anesthesia & Partial foot amputation (Chopart) & $35 \mathrm{~min}$ & 6.3 & 6.7 & & + & $20 \mathrm{~h}$ \\
\hline \multirow[t]{2}{*}{ DM 2, insulin treatment } & General anesthesia & Amputation of a digit & $20 \mathrm{~min}$ & 4.3 & 0 & + & + & \\
\hline & General anesthesia & Foot abscess, incision and drainage & $30 \mathrm{~min}$ & 3.3 & 0 & + & & \\
\hline DM 2, insulin treatment & General anesthesia & Amputation below knee & $60 \mathrm{~min}$ & 7.0 & 26.4 & & + & $20 \mathrm{~h}$ \\
\hline $\begin{array}{l}\text { DM 2, oral diabetic agents, } \\
\text { insulin treatment }\end{array}$ & Spinal anesthesia & FP bypass & $195 \mathrm{~min}$ & 7.6 & 24.8 & & + & $45 \mathrm{~h}$ \\
\hline DM 2, oral diabetic agents & General anesthesia & FP bypass & $180 \mathrm{~min}$ & 6.6 & 6.6 & + & + & $27 \mathrm{~h}$ \\
\hline DM 2, insulin treatment & & Prepared for FP bypass, MRI examination & & 5.2 & 0 & & + & \\
\hline DM 2, insulin treatment & Spinal anesthesia & Profundoplasty & $160 \mathrm{~min}$ & 6.4 & 0.2 & & & $23 \mathrm{~h}$ \\
\hline \multirow[t]{2}{*}{ DM 2, oral diabetic agents } & General anesthesia & 1. Aortobifemoral bypass & $240 \mathrm{~min}$ & 4.3 & 6.6 & + & + & $42 \mathrm{~h}$ \\
\hline & Spinal anesthesia & 2. Thrombectomy, endarterectomy & $120 \mathrm{~min}$ & & & & & \\
\hline DM 2, oral diabetic agents & Spinal anesthesia & Profundoplasty & $120 \mathrm{~min}$ & 13.7 & 5.1 & & & $19 \mathrm{~h}$ \\
\hline
\end{tabular}

Patient 17 underwent auxiliary magnetic resonance imaging, therefore CGM data from the first 18 hours only are stated (included the night before operation, preparation for operation, e.g. fasting and preoperative infusions).

Patient 18 underwent a planned aortobifemoral bypass surgery followed by an emergency reoperation (thrombectomy and embolectomy of the bypass) in the evening on the same day.

* IFCC approved nomenclature (one-time measurement)

** CGMS data.

$* * *$ Surgical ICU immediately after the surgery, with the exception of patient K.B. in her second monitored period (rank of the case No.5) who was hospitalised in cardiac ICU on her 4. postoperative day because of a coronary ischemic event.

to the value of plasma glucose (PG) concentration. This algorithm depends on the calibration value. The monitor displays a fresh calculation of PG every $5 \mathrm{~min}$. The system is capable reporting PG concentration in a limited range $2.2-22.5 \mathrm{mmol} / \mathrm{L}$ (39.6 - $405 \mathrm{mg} / \mathrm{dL})$, providing up to 288 recordings per day. A major advantage is that the trends e.g. the velocity of elevation or decrease in plasma glucose, are graphically visible. Retrospectively, all registered values can be displayed. It is possible to upload the data to a computer and obtain a statistical value distribution on individual days. A useful function is an event notification (the time of events as treatments, surgical procedures or meals can be recorded). The alarms could be set not only for reaching critical limits, but also upon anticipation of reaching a limit in a short time. In our observational study, we did not use the alarm function in order not to contribute to the patient's perioperative stress. The sensors were calibrated two times daily by the Wellion Linus glucometer (AgaMatrix, USA).

CGM was introduced on the day before surgery and continued for mostly 3 days with some exceptions. In one case the CGM was terminated prematurely because of the need for urgent magnetic resonance imaging. Some of the participants were monitored longer because of the postoperative metabolic instability. 
In addition to CGM, our patients had a laboratory $\mathrm{PG}$ profile (a capillary blood from a the fingerprick) scheduled at 6, 11 and 17 o' clock.

During the surgery, the paired values were taken by the point-of-care PG testing by the means of Wellion Linus glucometer (AgaMatrix, USA), 20 min before the start of the surgery and then every 15 - 20 min according to a preset protocol.

The body temperature was measured before and after the surgery and none of the patients was found febrile. A standard pain management following the procedurespecific recommendations was applied in all the patients, the pain control medication was titrated according the Visual Analogue Pain Intensity Score to grade 0 - 1.

\section{RESULTS}

\section{Applicability}

In contrast to a previous study ${ }^{41}$, we did not register any electromagnetic interference (no alarm, no loss of signal) with electrocauterisation during the surgery or with other electronic devices.

The coping with CGM was different for the nursing staff of the common surgery department and for the Intensive care setting (ICU) nursing staff. The ICU staff of all three centres were able to use the CGMS independently and to fully benefit from this technology, even maintaining the sensor longer than the planned 3 days in complicated cases with marked dysglycaemia. The insulin therapy was modified by the ICU attending physician. The nursing staff of the normal surgery department were less successful in using the information provided by the CGMS sufficiently, resulting in more patients outside the safe $P G$ ranges than expected.

Of 19 patients meeting the entry criteria, 17 agreed to take part in the study. It was their first experience of GGM for all of them. Three of them with marked perioperative dysglycaemia were offered CGM also during their reoperation, which followed few weeks after their first CGMS monitored surgery - all of them agreed.

The use of CGMS was well-tolerated by all patients, who mostly appreciated having continuous PG control. All ot them evaluated the initial sensor insertion procedure as minimally painful - less than the capillary blood sampling. Younger, "computer literate" patients tested their glycaemic sensitivity to particular meals and this helped them to overcome the healing period. Older patients were more inattentive to the new technology and some of them were stressed by the occasional noise of alarm caused by loss of signal, when they forgot the monitor behind them as they left their beds.

No adverse effects were registered even in patients with infection (diabetic gangrene with fever) or those who had the sensor inserted for 5 days or longer.

\section{Meeting the target glucose range $(4.4-11.1 \mathrm{mmol} / \mathrm{L})$ and a postoperative outcome}

We evaluated the PG data collected by CGM and the outcome of enrolled patients in all 20 perioperative cases.
We found an association between degree of perioperative dysglycaemia and postoperative outcome. The patients with marked stress-induced dysglycaemia more often needed a reoperation within next 3 months.

Only 4 out of 20 cases $(20 \%)$ met the criteria for the safe perioperative target glucose range $(4.4-11.1 \mathrm{mmol} / \mathrm{L})$. There was just one reoperation within 3 months needed in this group.

The group with maximal perioperative $P G$ value in the range $11.1-15.0 \mathrm{mmol} / \mathrm{L}$ accounted 6 cases with 3 reoperations within 3 months.

The maximal perioperative values of $\mathrm{PG}$ in the range $15.1-20.0 \mathrm{mmol} / \mathrm{L}$ were found in 7 cases, 6 of them needed a reoperation within 3 months.

There were three cases exceeding the perioperative PG value of $20.1 \mathrm{mmol} / \mathrm{L}$ and all of them needed a reoperation within 3 months.

\section{Accuracy}

We compared the values of plasma glucose $(\mathrm{PG})$ concentration referred by CGMS $(n=131)$ with those measured with a central laboratory analyser (a "gold standard") collected at the same time by regular capillary blood sampling (results in Table 2). The Wilcoxon signed-rank test ( 89 values) and paired Student's t-test (42 values) revealed no significant difference between the values of plasma glucose measured by CGM and by a laboratory analyser at $6 \mathrm{am}, 11 \mathrm{am}$ and $5 \mathrm{pm}$.

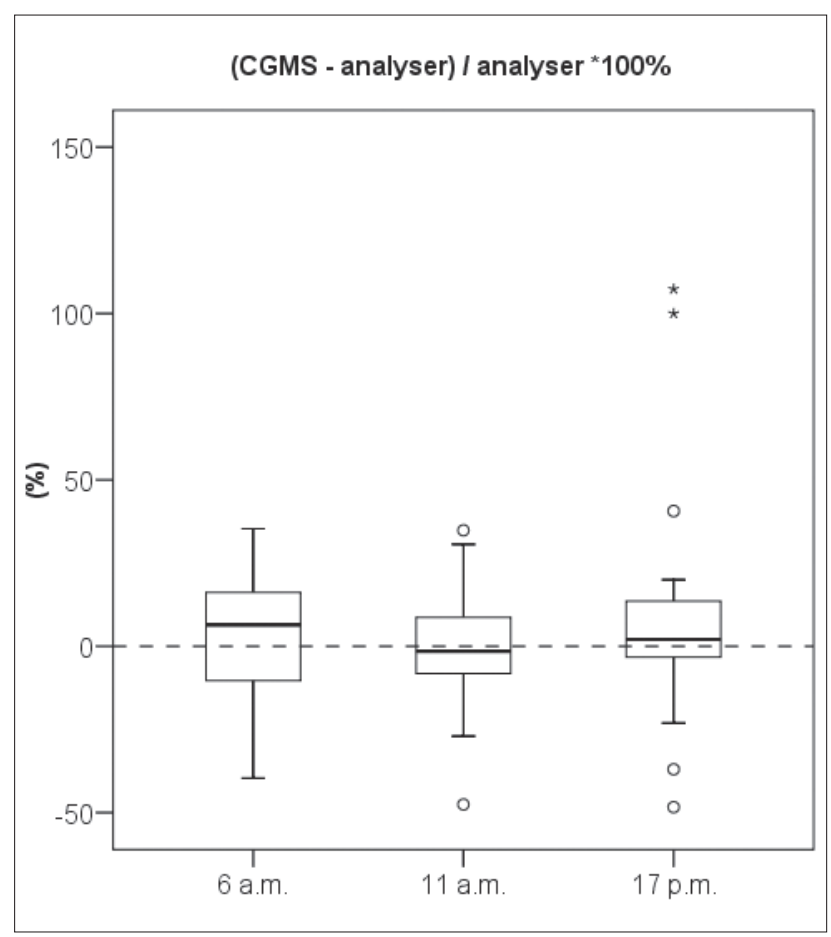

The horizontal line inside the quartile box plot represents the median (50th quartile), the bottom and top of the box are the 25 th and the 75 th percentiles (the lower and upper quartiles, respectively). The ends of the whiskers represent the minimum and maximum values. The outlying values are plotted as small circles, the extreme values are plotted as asterisks.

Fig. 1. The box-and-whisker plot shows the distribution of differences of plasma glucose values measured by the CGMS and the laboratory analyser (in \%). 


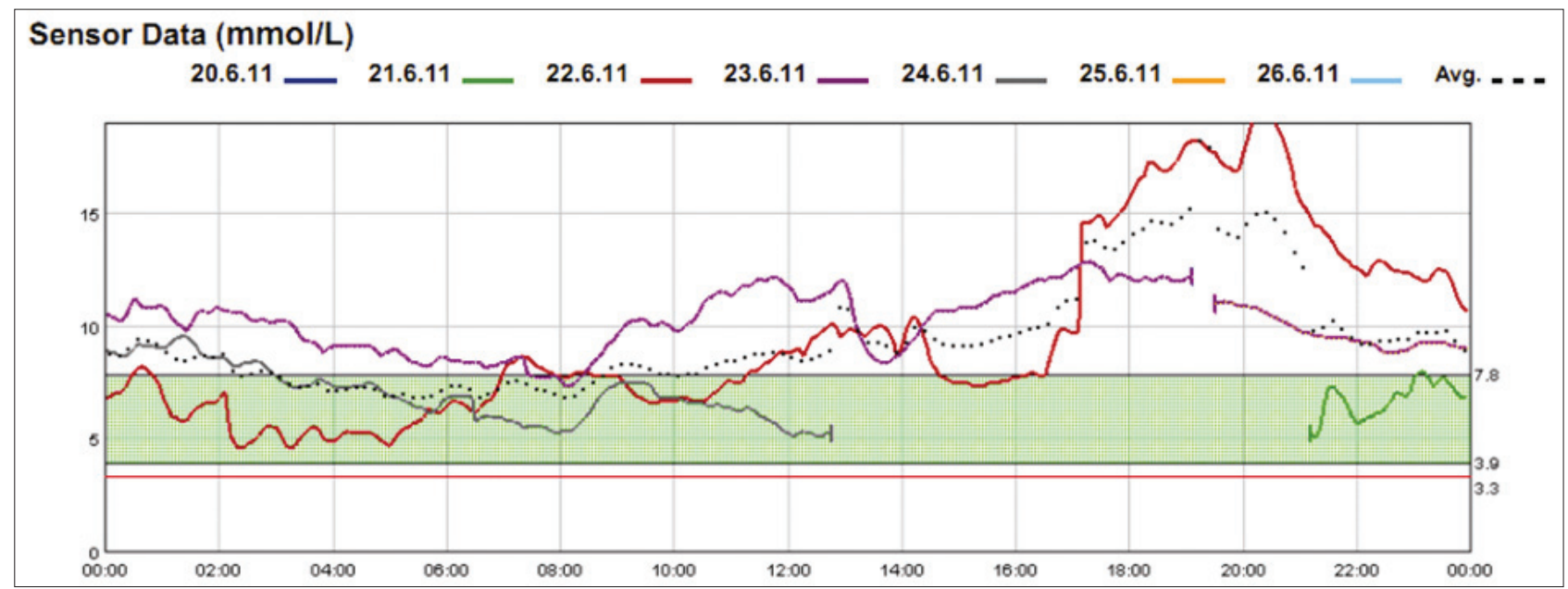

\begin{tabular}{|c|c|c|c|c|c|c|c|c|c|c|c|c|}
\hline \multicolumn{13}{|c|}{ Duration Distribution (hh:mm) } \\
\hline Above 7.8 & N/A & $0: 10$ & $12: 30$ & $52 \%$ & \multirow{2}{*}{$\begin{array}{r}22: 40 \\
1: 00\end{array}$} & $96 \%$ & $3: 00$ & $23 \%$ & \multirow{2}{*}{$\begin{array}{l}\text { N/A } \\
\text { N/A }\end{array}$} & N/A & \multirow{2}{*}{$\begin{array}{l}38: 20 \\
25: 00\end{array}$} & $61 \%$ \\
\hline \multirow{3}{*}{$\begin{array}{r}\text { Below } 3.9 \\
\text { Bentin }\end{array}$} & N/A & $2: 40 \quad 94 \%$ & $11: 30$ & $48 \%$ & & $4 \%$ & $9: 50$ & $77 \%$ & & N/A & & $39 \%$ \\
\hline & N/A & $0: 00$ & $0: 00$ & $0 \%$ & $0: 00$ & $0 \%$ & $0: 00$ & $0 \%$ & N/A & N/A & $0: 00$ & $0 \%$ \\
\hline & Mon 20 Jun & Tue 21 Jun & Wed 22 & Jun & Thu $23 \mathrm{~J}$ & & Fri 24 Jur & & Sat 25 Jun & Sun 26 Jun & Average $/ T$ & Total \\
\hline \# Sensor Values & 0 & 34 & 288 & & 284 & & 154 & & 0 & 0 & 760 & \\
\hline High SG (mmol/L) & N/A & 8.0 & 19.5 & & 12.9 & & 9.5 & & N/A & N/A & 19.5 & \\
\hline Low SG (mmol/L) & N/A & 5.0 & 4.6 & & 7.3 & & 5.1 & & N/A & N/A & 4.6 & 6 \\
\hline Average SG (mmol/L) & N/A & 6.7 & 9.5 & & 10.1 & & 7.0 & & N/A & N/A & 9.1 & 1 \\
\hline Standard Dev. & N/A & 0.8 & 4.0 & & 1.4 & & 1.2 & & N/A & N/A & 2.9 & 9 \\
\hline MAD \% & N/A & N/A & 20.5 & & 42.6 & & 30.5 & & N/A & N/A & 24.5 & \\
\hline \# Valid Calibrations & 0 & 1 & 6 & & 2 & & 1 & & 0 & 0 & 10 & 0 \\
\hline
\end{tabular}

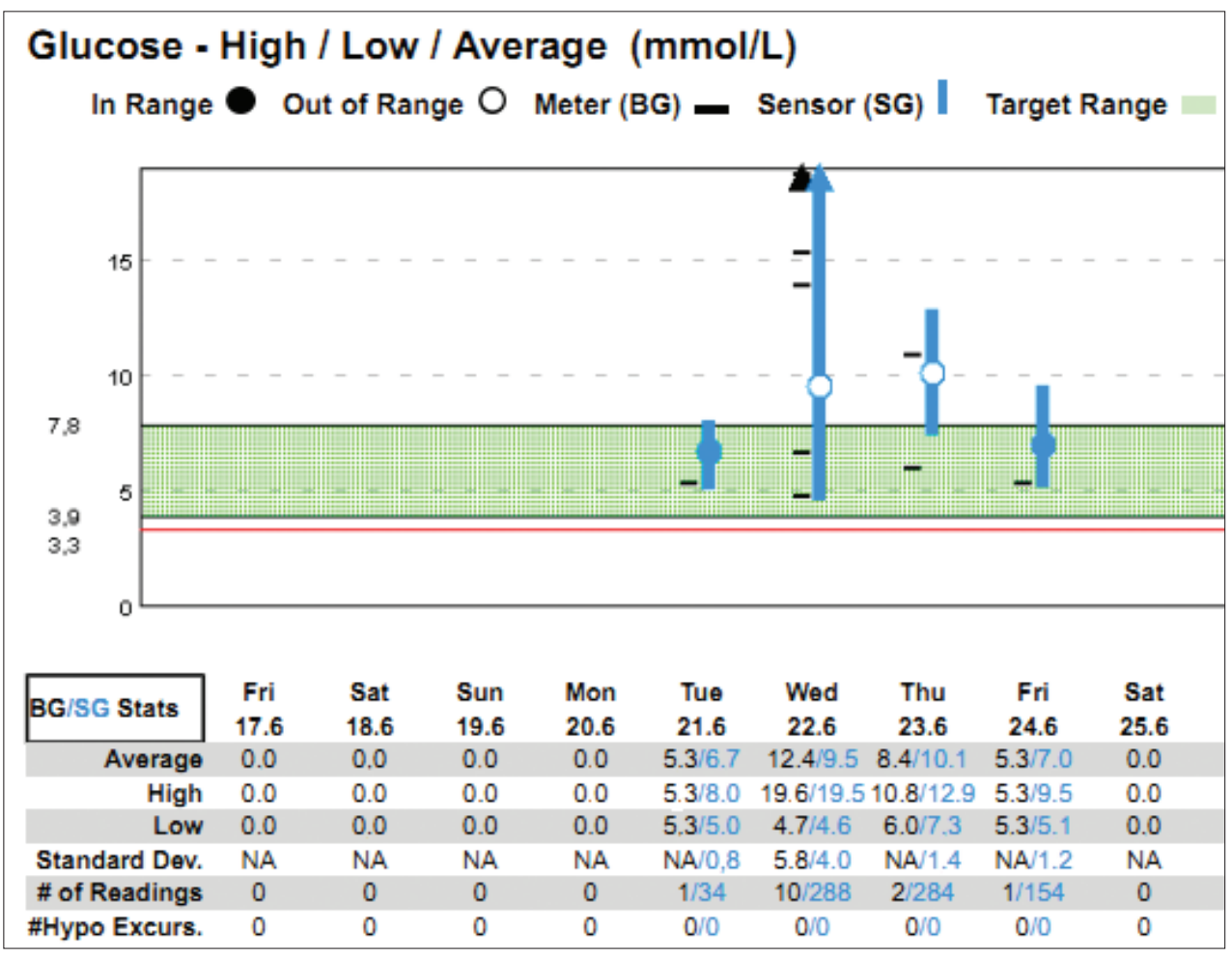

During the operation day, two glucose infusions were distributed: glucose $10 \% 500 \mathrm{~mL}$ with Humulin R 10 IU (6:30 - 8:50 am) and glucose $10 \% 500 \mathrm{ml}$ with Humulin R 12 IU (11:30 am $-1: 30 \mathrm{pm})$.

Fig. 2. K. K., M, 1947, type 2 DM. On 22. 6. 2011, profundoplasty, ilicoprofundal interposition, desobliteration of a. profunda femoris were performed under spinal anaesthesia $(2.30-4.30 \mathrm{pm})$. 
The box-and-whisker plot (Fig. 1) shows the distribution of the differences of the PG values referred by CGM and the laboratory analyser.

We correlated the values of $\mathrm{PG}$ concentration referred by CGM to the values obtained by the AgaMatrix Wellion Linus glucometer with respect to either the intraoperative period including 30 minutes after surgery $(n=51)$, the first postoperative day $(n=103)$ and the whole perioperative period $(n=350)$. Pearson's correlation coefficients were

$r=0.866$ for the intraoperative period, $r=0.903$ for the first postoperative day and

$r=0.875$ for the whole perioperative period (data collected from 71 perioperative days).

The accuracy of the sensor values with regard to the length of its insertion was also studied. The sensor was placed for 6 or more days in 4 cases. In one of them (Case 8 , see Table 1 ), there was a decline in accuracy during the $6^{\text {th }}$ day of use (difference of PG values between the sensor and central laboratory analyser was more than 3 $\mathrm{mmol} / \mathrm{L})$.

\section{Identification of patients profiting from CGMS}

CGM is not an expensive technology and it can be used to identify patients who are at risk of more serious perioperative dysglycaemia and who would benefit from continuous PG monitoring. In our experience, the risk factors are as follows:

1. DM treated with insulin or oral antidiabetic drugs

2. Ongoing infection, critical illness or additional metabolic imbalance

3. Preoperative glycated haemoglobin HbA1c (IFCC) above $7 \%$ (ref. ${ }^{13,43-45}$ ) or marked preoperative glycaemic variability (The interpretation of HbA1c should take into account recent blood transfusions, haemolytic processes, haemoglobinopathies etc.)

4. Corticosteroid medication

\section{DISCUSSION}

Ad I. We have some practical remarks on the feasibility of CGMS in the perioperative period. It is necessary to introduce the sensor at least $2 \mathrm{~h}$ before the intended monitoring. After the sensor acclimatisation in the subcutaneous tissue, the monitor requests the first calibration and immediately afterwards starts displaying the values of glycaemia.

The current disadvantage of transcutaneous CGMS in the in-patient setting is the limited reach of the transmitter signal $(2.5 \mathrm{~m})$ constituting complications especially during the transfer to the operation theatre. The gaps in glycaemia curves (Fig. 2 and 5) are caused by transient loss of signal when a monitor was accidentally removed from the reach of the transmitter. Improved telecommunication abilities (optimally reaching the central monitor in the nurses' room) would certainly promote CGMS applicability.

The limited range of $P G$ values measurement (with the Medtronic Guardian ${ }^{\circledR}$ REAL-Time CGMS from 2.2 to $22.5 \mathrm{mmol} / \mathrm{L}$ ) was exceeded in 3 cases of hypoglycaemia and in 6 cases of hyperglycaemia in our cohort. This limitatation could be a disadvantage in certain groups of patients (e.g. in hypoglycaemia measurement of premature neonates).

The correct interpretation of CGM data is substantial. We must consider a time lag between the value of PG concentration and the glucose concentratiomn measured in the interstitial fluid (IF) compartment. The IF glucose value could be delayed after the PG value by about 15 20 min (when PG concentration is on rise) and about 5 minutes (when it is descending). The time lag depends on the type of device.

We observed no adverse effects of CGMS use in our study. A small number of local complications have been described in the literature, ranging from minor complaints such as skin sensitisation to abscess formation ${ }^{46}$. Our results are in accordance with the evidence of low incidence of side effects caused by CGMS use.

Ad II. CGMS technology constitutes a step towards a personalised medicine. We demonstrate the most typical patterns of the perioperative PG development.

Even liberal control of PG is sometimes difficult to achieve. The reasons could be increased postoperative insulin resistance, unsuccessful control of infection, and also an uncertainty of the medical staff about the safe glycaemic range given that tight glycaemic control was found to be harmful. Some of the patients suffered from too high perioperative hyperglycaemia and a most did not meet the criteria for the safe blood glucose range. In this context, the CGM output in gross could be used as an indicator of the quality of care.

Hyperglycaemia was the most common problem, we also noticed mild asymptomatic hypoglycaemic episodes in 4 cases out of 20 cases.

The most serious consequence of perioperative hyperglycaemia is alteration of the immune response (phagocytosis and chemotaxis), resulting in impaired wound healing and higher postoperative sepsis rate. The infection and hyperglycaemia create a vicious cycle. The resolution of hyperglycaemia leads to normalisation of the inflammatory response ${ }^{47}$. Further sequelae of hyperglycaemia include increased blood viscosity, endothelial dysfunction and osmotic diuresis resulting in the loss of minerals and increased risk of dysrhythmias and ischemic events.

The most frequent patterns of perioperative glycaemia course are demonstrated in following diagrams 1. - 4. (Medtronic CareLink ${ }^{\mathrm{TM}}$ Personal Software ).

\section{Glycaemia peak on the day of surgery}

This is a typical perioperative evolution of glycaemia (Fig. 2).

\section{Persistent perioperative hyperglycaemia}

Persistent perioperative hyperglycaemia is a frequent perioperative record (Fig. 3). This complicated patient developed persistent postoperative hyperglycaemia exceeding the limit of sensor measurement capability 22.5 $\mathrm{mmol} / \mathrm{L}$ (405 mg/dL). The glucose control was surprisingly insufficient. He needed additional surgical proce- 


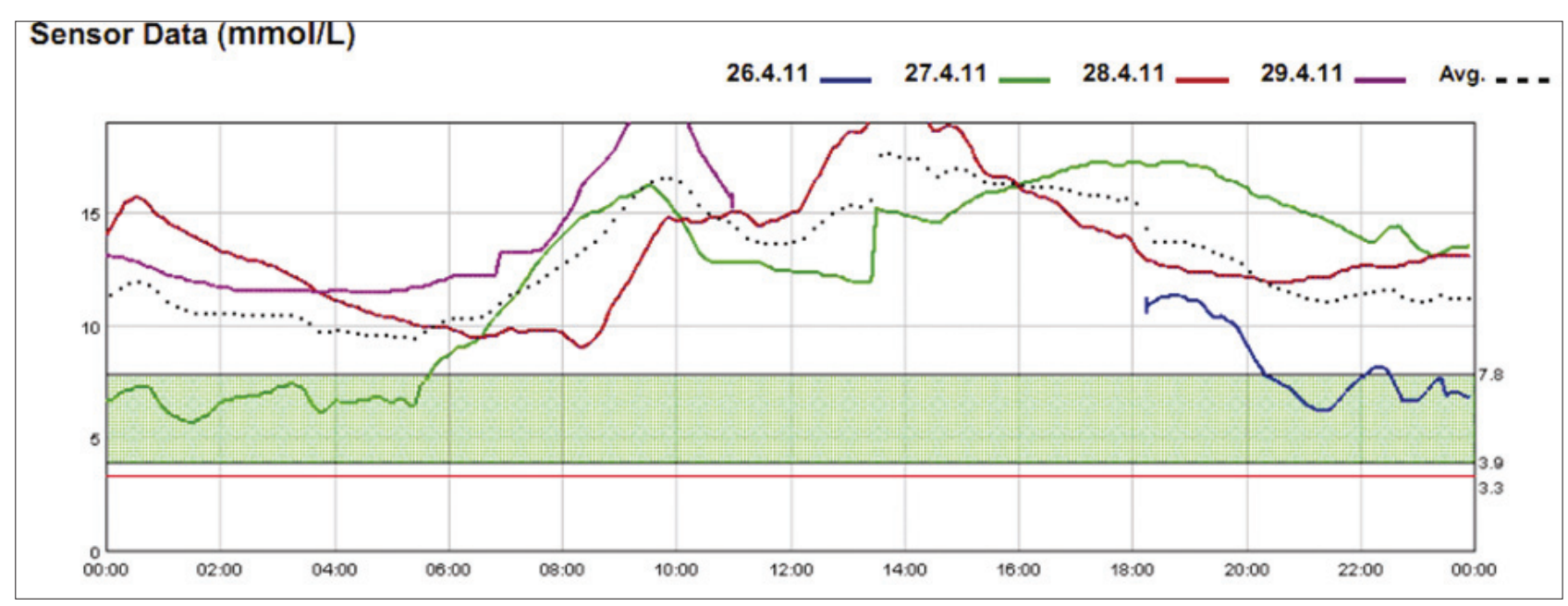

\section{Duration Distribution (hh:mm)}

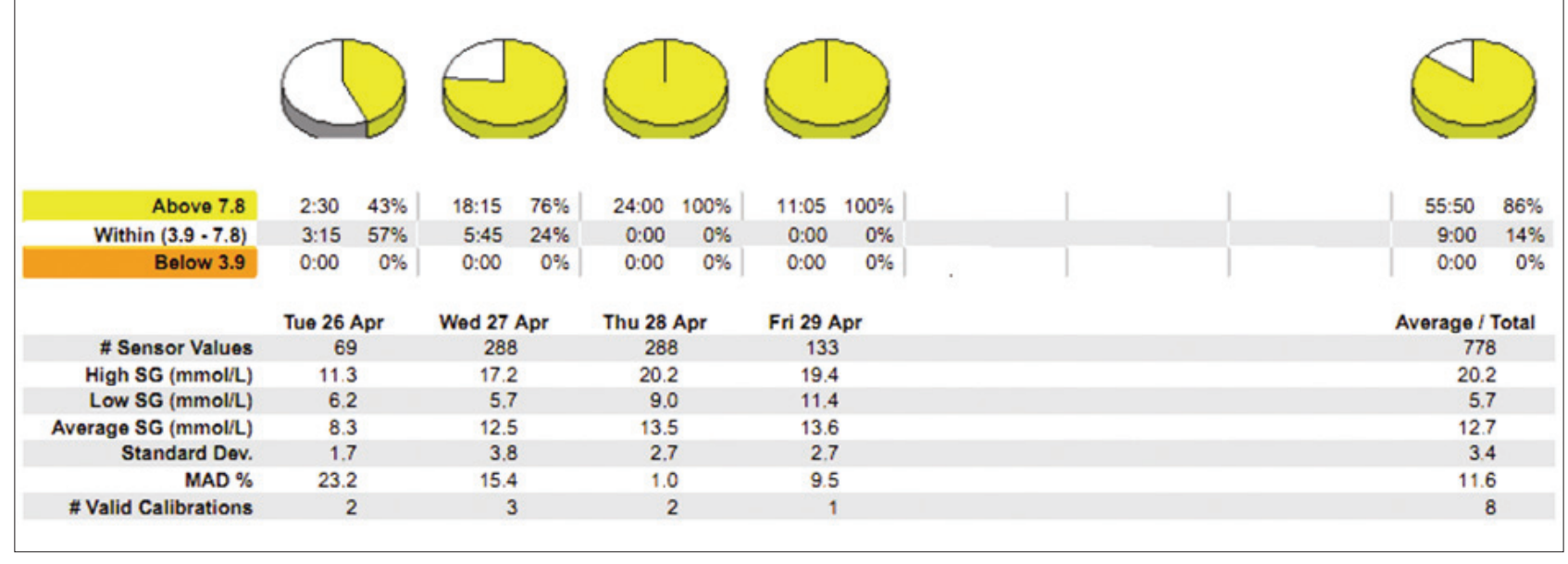

Glucose $10 \% 500 \mathrm{~mL}$ with Humulin R 12 IU was distributed from 6.50 to 9.00 am before the surgery.

Fig. 3. K. J., M, 1940, type 2 DM. On 27. 4. 2011, profundoplasty and a femoropopliteal bypass were performed under spinal anaesthesia (9:45 am - 1:00 pm).

dures because of ongoing wound infection. Patient with similar glycaemic course may benefit from the novel approach, a basal - bolus insulin therapy in the perioperative period $^{48}$.

\section{Tight glycaemic control with episodes of hypoglycemia}

In Fig. 4, an example of tight glycaemic control with episodes of hypoglycaemia is demonstrated. Such events would be underdiagnosed by conventional intermittent PG control.

In our group of patients, hypoglycaemia was registered in 4 cases only (20\%, see Table 1$)$. No hypoglycaemia event was reported during the surgery (bordeline values were registered for a short time only in the case in Fig. 5).

\section{Plasma glucose variability (enhanced by preoperative infusion)}

The patient in Fig. 5 had been prepared for the surgery, which was finally postponed to the next day. We suppose that his PG fluctuation was enhanced by preoperative infusions on both days.
In contrast, Fig. 6 presents the conventional PG profile of the same patient. In patients with similar high PG variability, we could be quite unaware of transient hypo- or hyperglycaemic excursions if the frequency of PG sampling is not high.

\section{Hunger after the surgery}

This curve illustrates a peculiar event. A patient did not adhere to the instructions given by the nursing staff and after the amputation of a digit under general anaesthesia, he consumed approximately $300 \mathrm{~g}$ of pastry immediately after coming back from the operating theatre to the ward. The resulting glycaemia peak, explained further by this event, is shown in Fig. 7.

Participants within the safe glucose range had the lowest incidence of reoperations. However, we can pose a question "What is the chicken and what is the egg?" - maybe the sickest patents are truly so sick that their PG levels are difficult to treat. Based on these results, it was impossible to discriminate whether a dysglycaemia 

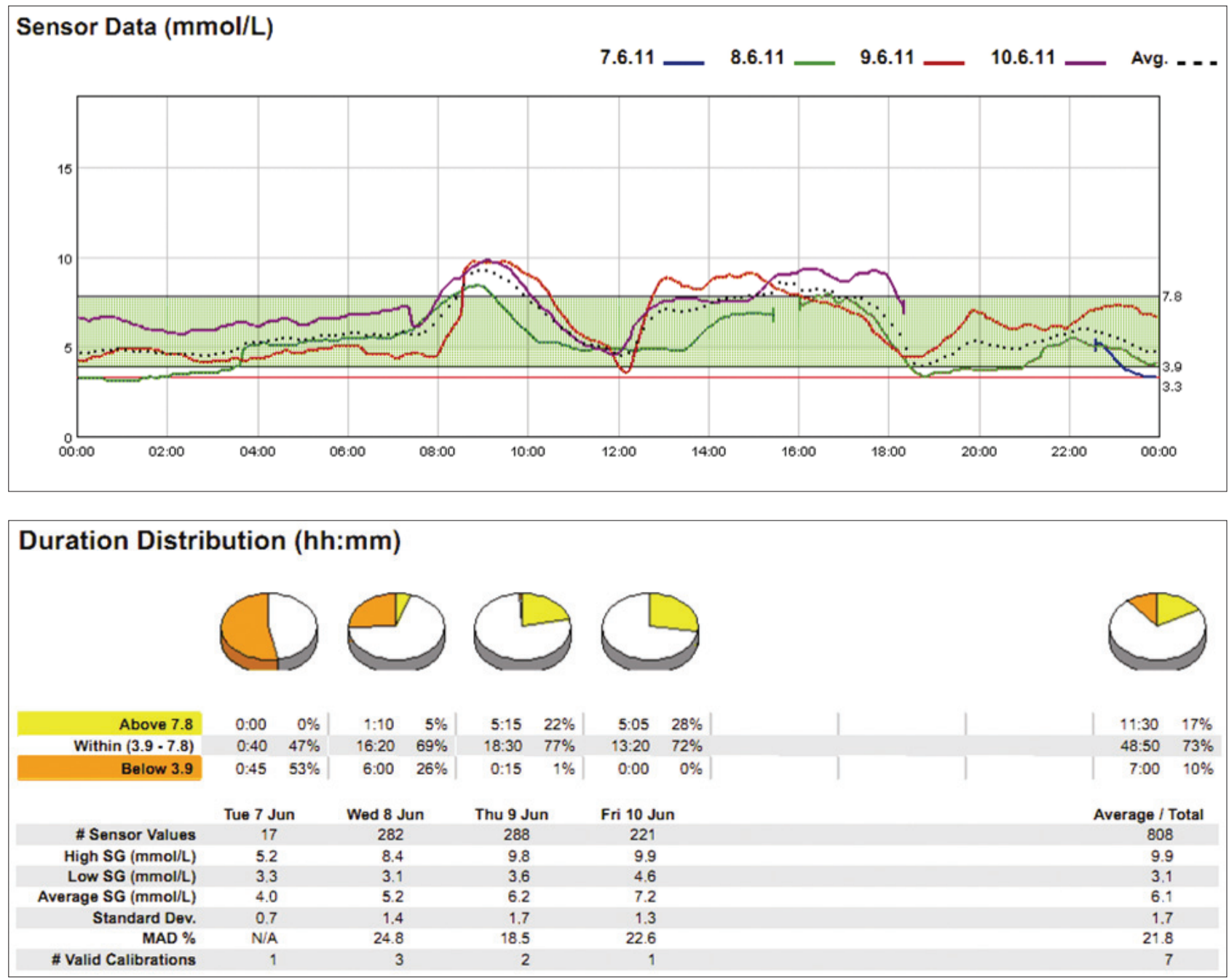

Too tight glycaemic control. Glucose 10\% $500 \mathrm{~mL}$ with Humulin R 12 IU 7:00 - 9:00 am on the day of surgery.

Fig. 4. G. J., F, 1938, type 2 DM. On 8. 6. 2011, incision and drainage of a foot abscess were performed under general anaesthesia $(12: 30 \mathrm{am}-1: 00 \mathrm{pm})$.

registered by CGM is a predictor of a negative outcome (e.g. a marker of impaired metabolic balance and insufficient control of infection) or a factor directly contributing to that negative outcome (due to metabolic changes and predisposition to infection). In any event, marked perioperative dysglycemia (Fig. 3 and 5) signals the need for additional therapeutic intervention - not only change of insulin therapy, but often also a decision about antibiotic therapy, sufficient surgical control of infection, more adequate pain therapy (in our group of patients the pain therapy was adequate), stress reduction etc.

The commonly distributed preoperative glucose infusion seems to be a frequent cause of perioperative PG spikes (example in Fig. 5).

Marked PG perioperative variability as shown in Fig. 5 is generally linked with poor outcome. Analogically to perioperative hyperglycaemia, it could be a secondary sign of a generally poor condition, but it may also contribute to it.

Although the sample size was too small to prove association between degree of perioperative dysglycemia and outome of surgery, our results confirm other studies ${ }^{4-9}$.
Ad III. Our study was an observational one. It will be interesting to plan an interventional study with a control group without CGM to prove the potentional benefit of CGM use on the postoperative outcome of the patients with DM. For future studies, we recommend the creation of CGM service team for surgery wards to supervise a correct calibration procedure and to help in the CGM implementation into routine nursing care. An important matching factor for the control group should be the degree of preoperative DM reflected in the glycated haemoglobin $\mathrm{HbA1c}$, together with the preoperative PG variability.

The pinpoint of our study was not to ascertain the accuracy of current CGMS - we consider this question as being already solved by larger studies mentioned above ${ }^{33-41}$. We focused on glycaemia trends of operated patients, on identification of frequent patterns of glycaemic reaction to stress and on the determination of eventual CGM impact on glycaemic stability in individual cases. Nevertheless we completed our observation by statistical analysis of the data which showed no statistical difference between CGMS and laboratory analyser data, and a strong correlation of CGMS and glucometer data. We found that 

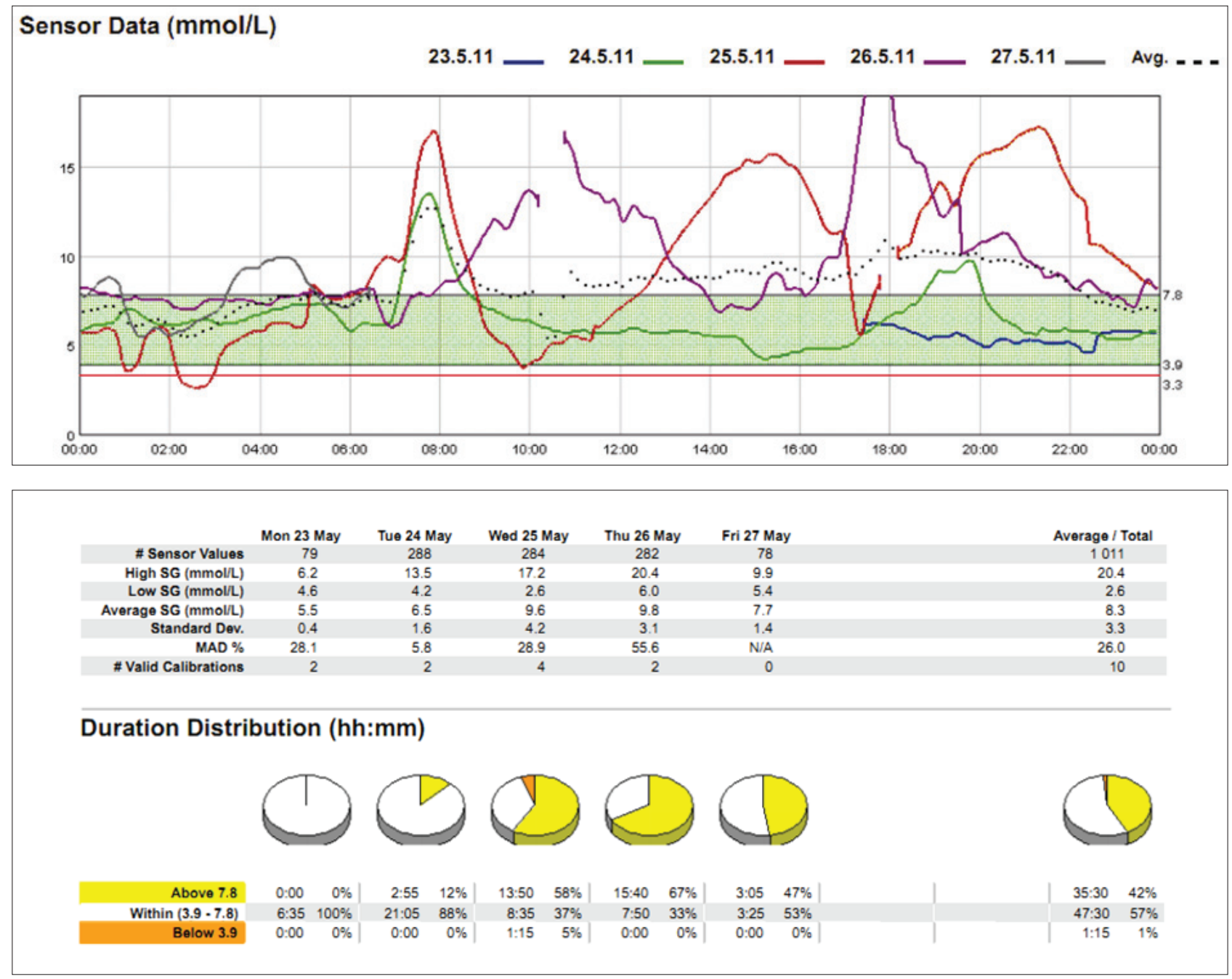

Glucose 10\% $500 \mathrm{~mL}$ with Humulin R 12 IU was distributed from 7:00 to 7:45 am before the surgery.

Fig. 5. Z. A., M, 1946, type 2 DM. 24. 5. 2011, prepared for operation, given an preoperative infusion (Glucose $10 \% 500 \mathrm{ml}$ with Humulin R 12 IU from 6:50 to 9:20 am) but the surgery was postponed. On 25. 5. 2011, a femoropopliteal bypass was performed (8.00 - $11.00 \mathrm{am})$ under general anaesthesia.

the difference between collected CGMS and glucometer data (e.g. the difference between the measurement from interstitial and capillary compartement) does not change substantionally between intraoperative, postoperative and whole perioperative time. The haemodynamic changes during the surgery and anaesthesia reduced the correlation only slightly. (The plasma - interstitium delay does not influence the correlation between the results of both methods of PG measurement, while these tests do not measure the absolute deviation between them).

The Wilcoxon signed-rank test ( 89 values) and paired Student's t-test ( 42 values) revealed no significant difference between the values of plasma glucose measured by CGM and by a laboratory analyser.

The significance of our statistical results is limited by small sample.

Despite this acceptable correlation, we found occasionally greater discrepancies (more than $2 \mathrm{mmol} / \mathrm{L}$ $=36 \mathrm{mg} / \mathrm{dL}$ PG concentration) between the values of CGMS and laboratory analyser ("gold standard") in some cases over limited periods of time. On our opinion, these inaccurate CGM was caused mostly by an improper calibration (the lack of supervising CGM team on standard wards) but we cannot rule out inaccuracies caused by local conditions in the tissue of the sensor insertion. These inaccurate measurements could cause a treatment mistake, if CGM is a stand-alone method of PG assessment.

Therefore we share a cautious conservative opinion: The CGM is useful in revealing the PG trends, alerts us in case of unexpected PG deviations (the speed of the change of PG trend indicates a need for initiating an approved laboratory test) and provides us with a complete information on the patient 's daily PG range, pattern and variability but laboratory checks of single values before the treatment decision are inevitable.

Until we have a new generation of "robust, high-performance sensors", the Rice's comparison is valid: PG values estimated by a laboratory analyser are like an accurate snapshot, CGM data are like a bit blurry movie but providing us with a real-time picture ${ }^{49}$. 


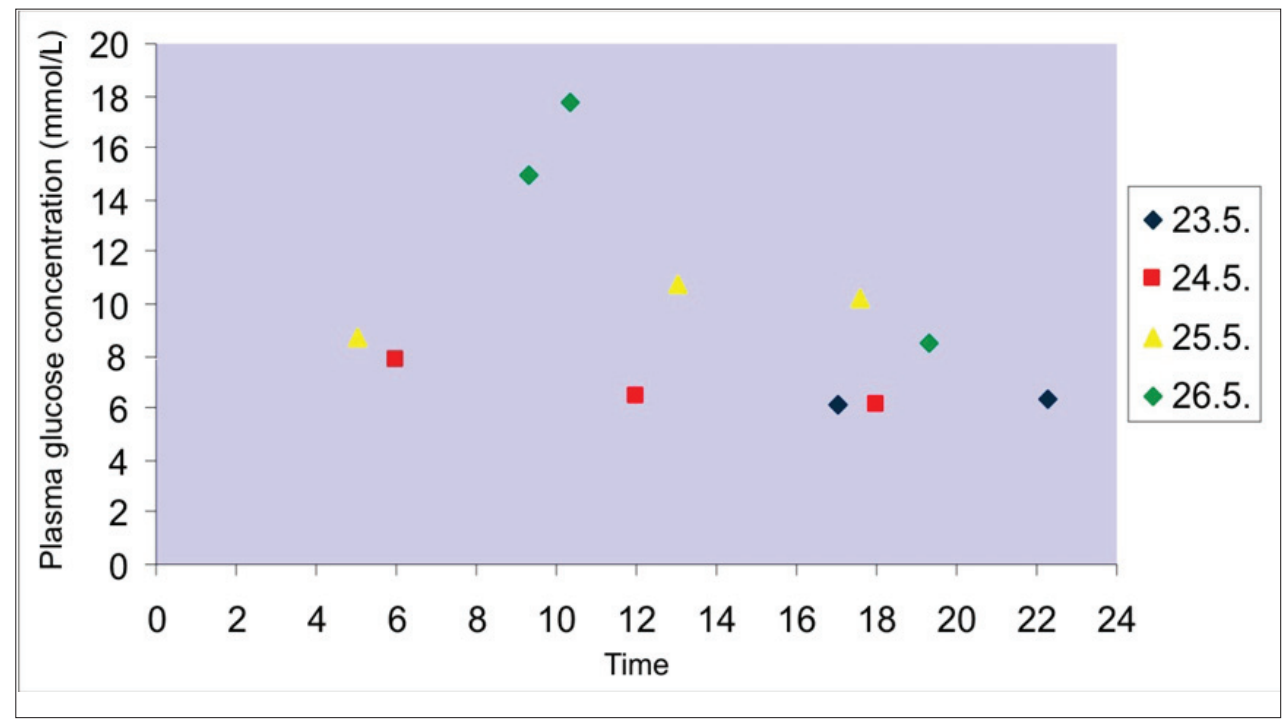

For the first three days, the values of glycaemia were "falsely" unremarkable.

Fig. 6. The same patient, conventional PG daily profile, central laboratory analyser.

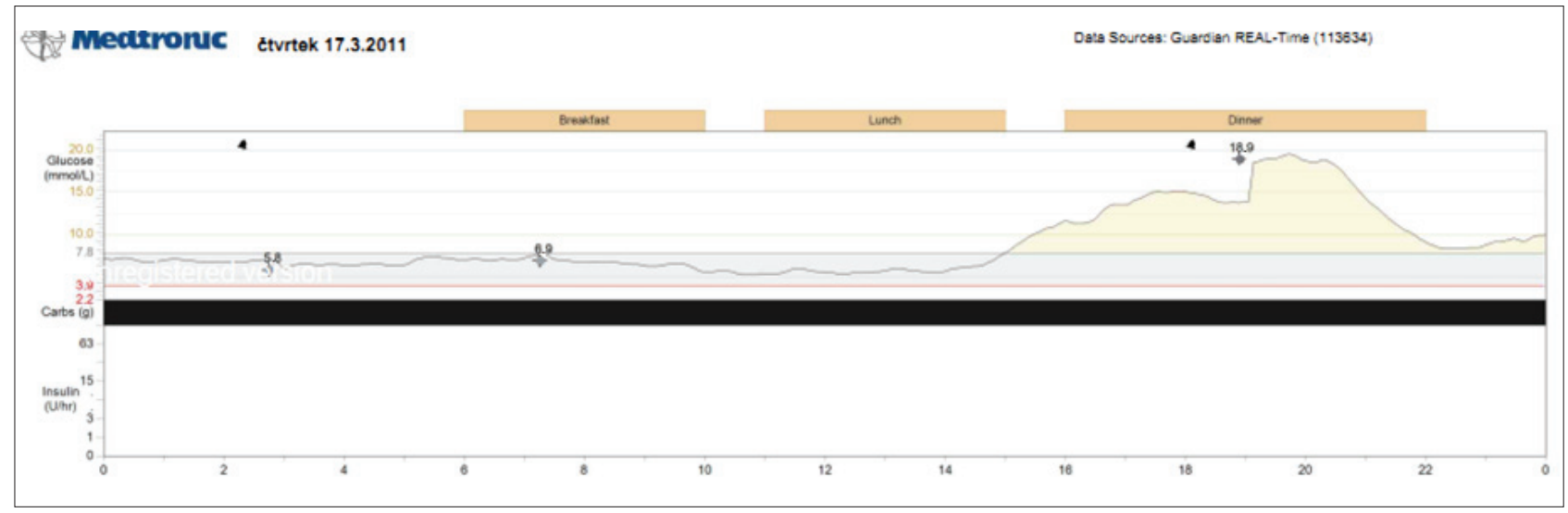

Glucose 10\% $500 \mathrm{~mL}$ with Humulin R 16 IU was distributed from 7:00 to 10:00 am before the surgery.

Fig. 7. S. F., M, 1938, type 2 DM . On 17. 3. 2011, amputation of a digit (12:40 am - 13:00 pm) was performed under general anaesthesia. The patient did not follow the instructions of the nursing staff and consumed a meal immediately after the surgery.

Due to the interstitium - plasma time lag phenomenon, subcutaneous CGM could never be $100 \%$ in accordance with the laboratory analyser - but provided this delay is similar to the delay between plasma and central nervous system glucose concentration, the IF glucose concentration more realistically reflects the central nervous glucose concentration than directly measured $\mathrm{PG}^{49}$. If this hypothesis is confirmed, it would be beneficial to display the original IF glucose concentration in addition to the calculated $P G$ value.

The correct use of CGM promotes its accuracy. The most essential procedure is a correct calibration, with an externally gained value of PG being set to the monitor. Calibration is required twice daily, in the time when no fluctuations in PG are expected (it is incorrect to calibrate during or after the meal, during or after glucose or insulin administration etc.). In case of unexpected discrepancy between CGM and laboratory data it is good to perform an extra calibration during the day; a more frequent calibration ( 4 times a day) leads perhaps to more accurate performance of the sensor ${ }^{50}$. It is essential to calibrate with the most accurate device available, preferably with a laboratory or blood gas analyser. Our pilot study was performed on standard surgery wards without this opportunity, so we used the Wellion Linus glucometer (AgaMatrix, USA) based on technology which prevents the glucose reading to be influenced by the level of haematocrit ${ }^{51}$. None of our patients was calibrated in the state of hypoperfusion.

The performance of the Medtronic sensor is guaranteed for 6 days and may work well much longer ${ }^{52,53}$. Even so a gradual decline of accuracy with the time is sometimes observed due to the biofilm formation on the sensor surface, subclinical inflammatory response to a foreign body and formation of reactive oxygen species (ROS) interfering with electrochemical sensing ${ }^{54,55}$. In such case, 
the sensor should be removed and replaced. We registered a progressive decline of accuracy in Case 8 (see Table 1) during the 6 th day of use (the sensor was removed on the same day). The difference of PG values was more than $3 \mathrm{mmol} / \mathrm{L}$ ( $54 \mathrm{mg} / \mathrm{dL}$ ) between the sensor and laboratory analyser. This patient had the highest preoperative HbAlc value and a high perioperative PG variability confirmed also by laboratory analyser. If this could be a factor contributing to the quicker loss of sensor function is not clear and needs further exploration.

Although the debate on CGM accuracy continues, there are some issues where continuous glycaemia monitoring is preferable. PG variability was recently found to be associated with a worse clinical outcome, and CGM is perhaps the most suitable technology for PG variability calculation. CGM could be useful in collecting the data to define the optimal glycaemia management strategies of different groups of surgical patients (with SID, with or without DM, critically ill or not, type of surgery, various populations and therapeutic strategies, etc.) and it could also help us to gain the data for comparing the influence of different kinds of anaesthesia on insulin sensitivity ${ }^{56}$.

Ad IV. In personalised medicine, the perioperative use of CGMS could be helpful especially in cases of complicated metabolic disorders.

\section{CONCLUSION}

Although subcutaneous CGMS have accuracy limitations compared to central laboratory devices and are not applicable as a stand-alone method for intraoperative PG monitoring, they may still be helpful to individualize treatment. The CGMS technology is safe and has the potential to develop into a new standard for perioperative surveillance, contributing to a detailed investigation of the perioperative homeostasis. Further studies with a new generation of "high performance" sensors and monitors with upgraded options would be desirable to evaluate a potentional benefit for keeping the patient within the safe $\mathrm{PG}$ range in the dynamic perioperative period.

\section{ACKNOWLEDGEMENTS}

We would like to thank Jarmila Indrakova, MD (Department of Surgery II - Vascular and Transplantation Surgery, University Hospital Olomouc and Faculty of Medicine and Dentistry, Palacky University Olomouc, Czech Republic), Daniel Siska, MD (Department of Anaesthesiology and Intensive care Medicine, University Hospital Olomouc and Faculty of Medicine and Dentistry, Palacky University Olomouc, Czech Republic) to the staff of the Department of Surgery, Kromeriz Hospital a.s., Kromeriz, Czech Republic for their assistance with data collection, and to Marian Poljak, Adam Tancred and Zdenka Michalikova for their help with this article.

This work was supported by the research grant IGA UP LF 2010/009 from Palacky University Olomouc, Czech Republic.

\section{CONFLICT OF INTEREST STATEMENT}

Author's conflict of interest disclosure: The authors state that there are no conflicts of interest regarding the publication of this article.

\section{REFERENCES}

1. Van den Berghe $G$, Wouters $P$, Weekers MF, Verwaest $C H$, Bruyninckx F, Schetz M, Vlasselaers D, Ferdinande P, Lauwers P, Bouillon R. Intensive insulin therapy in critically ill patients. N Engl J Med 2001;345(19):1359-67.

2. Kansagara $D$, Fu R, Freeman $M$, Wolf $F$, Helfand $M$. Intensive insulin therapy in hospitalized patients: a systematic review. Ann Intern Med 2011;154(4):268-82.

3. Kao LS, Meeks D, Moyer VA, Lally KP. Peri-operative glycemic control regimens for preventing surgical site infections in adults. Cochrane Database Syst Rev 2009,3: CD006806.

4. Gandhi GY, Nuttall GA, Abel MD, Mullany $\mathrm{CH}$, Schaff HV, O'Brien PC, Johnson MG, Williams AR, Cutshall SM, Mundy LM, Rizza RA, McMahon MM. Intraoperative hyperglycemia and perioperative outcomes in cardiac surgery patients. Mayo Clin Proc 2005;80(7):862-6.

5. Olsen MA, Nepple JJ, Riew KD, Lenke LG, Bridwell KH, Mayfield J, Fraser VJ. Risk factors for surgical site infection following orthopaedic spinal operations. J Bone Joint Surg Am 2008;90(1):62-9.

6. Ambiru S, Kato A, Kimura F, Shimizu A, Yoshidome H, Otsuka M, Miyazaki M. Poor postoperative blood glucose control increases surgical site infections after surgery for hepato-biliary-pancreatic cancer: a prospective study in a high-volume institute in Japan. J Hosp Infect 2008;68(3):230-3.

7. Vilar-Compte D, de Iturbe IA, Martin-Onraet A, Pérez-Amador M, Sánchez-Hernández C, Volkow P. Hyperglycemia as a risk factor for surgical site infections in patients undergoing mastectomy. Am J Infect Control 2008;36(3):192-8.

8. Lipshutz AKM, Gropper MA. Perioperative Glycemic Control: An Evidence-based Review. Anesthesiology 2009;110(2):408-21.

9. McGirt MJ, Woodworth GF, Brooke BS, Coon AL, Jain S, Buck DS, Huang J, Clatterbuck RE. Hyperglycemia Independently Increases the Risk of Perioperative Stroke, Myocardial Infarction, and Death after Carotid Endarterectomy. Neurosurgery 2006;58(6):1066-73.

10. Pierre EJ, Barrow RE, Hawkins HK, Hal K, Nguyen TT, Sakurai Y, Desai $M$, Wolfe RR, Herndon DN. Effects of insulin on wound healing. J Trauma 1998,44(2):342-5.

11. Hennessey PJ, Black CT, Andrassy RJ. Epidermal Growth Factor and Insulin Act Synergistically During Diabetic Healing. Arch Surg 1990;125(7):926-9.

12. Rice MJ, Pitkin AD, Coursin, DB. Glucose measurement in the operating room: More complicated than it seems. Anesth Analg 2010;110:1056-65.

13. Moghissi ES, Korytkowski MT, DiNardo M, Einhorn D, Hellman R, Hirsch B, Ismail-Beigi F, Kirkman MS, Umpierrez GE. American Association of Clinical Endocrinologists and American Diabetes Association (AACE) consensus statement on inpatient glycemic control. Diabetes Care 2009;32(6):1119-31.

14. Joshi GP, Chung F, Vann MA, Ahmad S, Gan TJ, Goulson DT, Merill DG, Twersky R. Society for Ambulatory Anesthesia consensus statement on perioperative blood glucose management in diabetic patients undergoing ambulatory surgery. Anesth Analg 2010;111(6):1378-87.

15. Sheehy AM, Gabbay RA. An overview of preoperative glucose evaluation, management, and perioperative impact. J Diabetes Sci Technol 2009;3(6):1261-9.

16. Egi M, Bellomo R, Stachowski E. Circadian rhythm of blood glucose values in critically ill patients. Crit Care Med 2007;35:416-21.

17. Dellinger RP, Levy MM, Rhodes A, Annane D, Gerlach H, Opal SM, Sevransky JE, Sprung CHL, Douglas IS, Jaeschke R, Osborn TM, Nunnaly ME, Townsend SR, Reinhart K, Kleinpell RM, Angus DC, Deutschman CS, Machado FR, Rubenfeld GD, Webb S, Beale JR, Vincent $J$, Moreno R. Surviving Sepsis Campaign guidelines for management of severe sepsis and septic shock. Intensive Care Med 2013;39(2):165-228.

18. Pronovost PJ, Goeschel CA, Wachter RM. The wisdom and justice of not paying for "preventable complications". JAMA 2008;299:2197-9. 
19. Finkielman JD, Oyen LJ, Afessa B. Agreement between bedside blood and plasma glucose measurement in the ICU setting. Chest 2005;127:1749-51.

20. Kanji S, Buffie J, Hutton B, Bunting PS, Singh A, McDonald K, Fergusson D, Mclntyre LA, Hebert PC. Reliability of point-of-care testing for glucose measurement in critically ill adults. Crit Care Med 2005;33(12):2778-85.

21. Rice MJ, Pitkin AD, Coursin, DB. Glucose measurement in the operating room: More complicated than it seems. Anesth Analg 2010;110:1056-65.

22. Desachy A, Vuagnat AC, Ghazali AD, Baudin OT, Longuet $\mathrm{OH}$, Calvat $\mathrm{SN}$, Gissot V. Accuracy of bedside glucometry in critically ill patients: Influence of clinical characteristics and perfusion index. Mayo Clin Proc 2008;83(4):400-5.

23. Atkin SH, Dasmahapatra A, Jaker MA, Chorost MI, Reddy S. Fingerstick glucose determination in shock. Ann Intern Med 1991;114(12):10204.

24. Bochicchio G, Joseph J, Magee M, Gulino A, Higgins M, L, Peyser T, Simpson P, Leach J, Kamath A, Edwards Lifesciences. Multicenter Evaluation of A First Generation Automated Blood Glucose Monitor in the or/lcu. Critical Care Medicine 2011;39(12):55.

25. Torjman MC, Dalal N, Goldberg ME. Glucose Monitoring in Acute Care: Technologies on the Horizon. J Diabetes Sci Technol 2008;2(2):178-81.

26. Pichardo-Lowden A, Gabbay RA. Management of Hyperglycaemia During the Perioperative Period. Curr Diab Rep 2012;12(1):108-18.

27. Hanazaki K., Maeda H. Relationship between perioperative glycemic control and postoperative infections. World J Gastroentero 2009,15(33):4122-5.

28. Joseph Jl, Hipszer B, Mraovic B, Chervoneva I, Joseph M, Grunwald Z. Challenges in Glycemic Control in Perioperative and Critically III Patients. Clinical Need for Continuous Glucose Monitoring in the Hospital. J Diabetes Sci Technol 2009;3(6):1309-18.

29. Hanazaki K, Okabayashi T. What Should the Targeted Range of Blood Glucose Levels Be to Reduce the Incidence of Surgical Site Infection Following General Surgery? Arch Surg 2011;146(3):368-9.

30. Tsukamoto Z, Okabayashi T. Progressive artificial endocrine pancreas: The era of novel perioperative blood glucose control for surgery. Surg today 2011;41(10):1344-51.

31. Takahashi G., Sato N, Matsumoto N, Shozushima T, Hoshikawa K, Akitomi S., Kikkawa T, Onodera C, Kojika M, Inoue Y, Suzuki K, Wakabayashi G, Endo S. Preliminary Study on Glucose Control with an Artificial Pancreas in Postoperative Sepsis Patients. Eur Surgl Res 2011;47(1):32-8.

32. Kovatchev B, Anderson S, Heinemann L, Clarke W. Comparison of the Numerical and Clinical Accuracy of Four Continuous Glucose Monitors. Diabetes Care 2008;31(6):1160-4

33. Logtenberg SJ, Kleefstra N, Snellen F, Groenier KH, Slingerland RJ, Nirch AP, Hilo BJ. Pre- and Postoperative Accuracy and Safety of a Real-Time Continuous Glucose Monitoring System in Cardiac Surgical Patients: A Randomized Pilot Study. Diabetes Technol Ther 2009;11(1):31-7.

34. Goldberg PA, Siegel MD, Rusell RR, Sherwin RS, Halickman Jl, Cooper DA, Dziura JD, Inzucchi SE. Experience with the Continuous Glucose Monitoring System ${ }^{\circledast}$ in a Medical Intensive Care Unit. Diabetes Technol Ther 2004;6(3):339-47.

35. Allen HF, Rake A, Roy M, Brenner D, McKiernan CHA. Prospective detection of hyperglycemia in critically ill children using continuous glucose monitoring. Pediatr Crit Care Med 2008;9(2):153-8.

36. Brunner R, Kitzberger R, Miehsler W, Herkner $\mathrm{H}$, Madl CH, Holzinger $\mathrm{U}$. Accuracy and reliability of a subcutaneous continuous glucose-monitoring system in critically ill patients. Crit Care Med 2011;39(4):659-64.

37. Holzinger U, Warszawska J, Kitzberger R., Wewalka m, Miehsler W, Herkner H, Madl CH. Real-time continuous glucose monitoring in critically ill patients: A prospective randomized trial. Diabetes Care 2010;33:467-72.
38. Holzinger U, Warszawska J, Kitzberger R., Herkner H, Metnitz PGH, Madl $\mathrm{CH}$. Impact of shock requiring norepinephrine on the accuracy and reliability of subcutaneous continuous glucose monitoring Intensive Care Med 2009;35(8):1383-9.

39. Stoszkova A, Dostal P, Musil F, Smahelova A, Zadak Z, Cerny V. Blood and tissue glucose level in critically ill patients: a comparison of different methods of measuring interstitial glucose levels. Intensive Care Med 2009;35:1318.

40. Ligtenberg JJ, Borggreve HF, Sternerdink A, Zijstra JG. Subcutaneous glucose measurements and glucose regulation (?). Intensive Care Med 2010,36:897-8.

41. Piper HG, Alexander JL, Shukla A, Pigula F, Costello JM, Laussen PC, Jaksic T, Agus MSD. Real-time continuous glucose monitoring in pediatric patients during and after cardiac surgery. Pediatrics 2006;118(3):1176-84

42. Vriesendorp TM, Devries JH, Holleman F, Dzoljic M, Hoekstra JBL. The Use of Two Continuous Glucose Sensors During and After Surgery. Diabetes Technol Ther 2005;7(2):315-22.

43. Sato H., Carvalho G, Sato T, Lattermann R, Matsukawa T, Schricker $\mathrm{T}$. The association of preoperative glycemic control, intraoperative insulin sensitivity and outcomes after cardiac surgery. J Clin Endocrinol Metab 2010;95(9):4338-44.

44. Gustafsson UO, Thorell A, Soop, M, Nygren J. Haemoglobin A1c as a predictor of postoperative hyperglycaemia and complications after major colorectal surgery. Br J Surg 2009;66(11):1358-64.

45. Standards of medical care in diabetes - 2011. Diabetes Care 2011;3(Suppl1):11-61. (Guideline from the ADA for inpatient glycemic care.)

46. Jadviščoková T, Fajkusová Z, Pallayová M, Luza J, Kuzmina G. Occurence of adverse events due to continuous glucose monitoring. Biomed Pap Med Fac Univ Palacký Olomouc Czech Rep 2007;151(2):263-6.

47. Dungan KM, Braithwaite SS, Preiser JC. Stress hyperglycaemia. Lancet 2009;373(9677):1798-807.

48. Umpierrez G, Smiley D, Jacobs S, Peng L, Temponi A, Mulligan P, Umpierrez D, Newton CH, Olson D, Rizzo M. Randomized Study of Basal - Bolus Insulin Therapy in the Inpatient Management of Patients With Type 2 Diabetes Undergoing General Surgery (RABBIT 2 Surgery). Diabetes Care 2011;34(2):256-61.

49. Rice MJ, Coursin DB. Continuous Measurement of Glucose: Facts and Challenges. Anesthesiology 2012;116(1):199-204.

50. Mader JK, Korsatko S, Bock G., Feichtner G, Pachler C, Plank J, Ellmerer M, Pieber TR. Continuous subcutaneous monitoring in different groups of critically ill patients. Wien Klin Wochenschr,2010;122:14

51. Chlup R, Doubravova B, Peterson K, Zapletalova J, Bartek J. Wawesense technology glucometer Linus for routine self-monitoring and clinical practice. Acta diabetol 2011;48(1):35-40.

52. Peterson K, Zapletalova J, Kudlova P, Matuskova V, Bartek J, Novotny D, Chlup R. Benefits of three-month continuous glucose monitoring for persons with diabetes using insulin pumps and sensors. Biomed Pap Med Fac Univ Palacky Olomouc Czech Rep 2009;153(1):47-52.

53. Chlup R, Jelenova D, Chlupova K, Zapletalova J, Chlupova L, Bartek J. Function and accuracy of glucose sensors beyond their stated expiry date. Diabetes Technol Ther 2006;8(4):495-504.

54. Iscoe KE, Davey RJ, Fournier PA. Is the Response of Continuous Glucose Monitors to Physiological Changes in Blood Glucose Levels Affected by Sensor Life? Diabetes Technol Ther 2012;14(2):135-42.

55. Klueh U, Kaur M, Oiao Y, Kreutzer D. Critical role of tissue mast cells in controlling long-term glucose sensor function in vivo. Biomaterials 2010;31(16):4540-51.

56. Anderson RE, Ehrenberg J, Barr G, Brismar K, Övall A, Alserius T, Ivert T. Effects of thoracic epidural analgesia on glucose homeostasis after cardiac surgery in patients with and without diabetes mellitus. Eur J Anaesthesiology 2005;22(7):524-9. 